\title{
Os princípios da Atividade Orientadora de Ensino (AOE) e a Educação Escolar como direito
}

\author{
Susimeire Vivien Rosotti de Andrade \\ Patrícia Sandalo Pereira \\ Anemari Roesler Luersen Vieira Lopes
}

\begin{abstract}
Resumo: Neste artigo compartilha-se uma pesquisa cujos fundamentos teórico-metodológicos partem da Perspectiva Histórico-Cultural em consonância com o Materialismo Histórico-Dialético (MHD). Concebe que o direito à educação escolar decorre desta acarretar mais implicações na formação e desenvolvimento humano. Assim, busca apresentar uma investigação teórico-bibliográfica da relação dos princípios da Atividade Orientadora de Ensino ( $A O E$ ) e a educação escolar como direito. A questão norteadora é: qual a relação entre a $\mathrm{AOE}$ e a educação escolar como direito? A pesquisa demonstra que os princípios pautados pela AOE afirmam a educação escolar como Atividade que visa a unidade entre o trabalho do professor e do aluno preconizando a formação e o desenvolvimento humano para transformação da sociedade. Considera que 0 estudo desta relação é importante no nicho presente, tendo em vista que desvela a importância deste direito estar previsto na legislação, declarado como fundamental e 0 Estado 0 responsável pela garantia deste ser público subjetivo.
\end{abstract}

Palavras-chave: Formação e desenvolvimento humano. Educação escolar. Direito. Perspectiva HistóricoCultural.

Susimeire Vivien Rosotti de Andrade Doutora em Educação Matemática pela Universidade Federal do Mato Grosso do Sul. Professora da Universidade Estadual do Oeste do Paraná, Foz do Iguaçu, Paraná, Brasil.

iD https://orcid.org/0000-0001-9188-8620

$\triangle$ susimeire.andrade@unioeste.br

Patrícia Sandalo Pereira Doutora em Educação Matemática pela Universidade Estadual Paulista Júlio de Mesquita Filho. Professora da Universidade Federal do Mato Grosso do Sul, Campo Grande, Mato Grosso do Sul, Brasil Estado.

iD https://orcid.org/0000-0002-7554-0058 $\bowtie$ sandalo.patricia13@gmail.com

Anemari Roesler Luersen Vieira Lopes Doutora em Educação pela Universidade de

São Paulo. Professora da Universidade

Federal de Santa Maria, Santa Maria, Rio Grande do Sul. Brasil.

iD https://orcid.org/0000-0002-4636-9618 $\bowtie$ anemari.lopes@gmail.com

Recebido em 29/04/2021 Aceito em 30/06/2021 Publicado em 21/08/2021

\section{The principles of the Teaching Guiding Activity (AOE) and School Education as a law}

Abstract: This article shares a research whose theoretical-methodological foundations start from the Historical-Cultural Perspective in consonance with Historical-Dialectical Materialism (MHD). Conceives that the right to school education stems from this entail more implications in training and human development. Thus, it seeks to present a theoretical-bibliographic investigation of the relation of the principles of the Teaching Guiding Activity $(\mathrm{AOE})$ and school education as a law. The guiding question is: what is the relationship between the $A O E$ and school education as a right? The research shows that the principles guided by the AOE affirm school education as an activity that aims at the unity between the work of the teacher and the student advocating formation and human development for the transformation of society. Considers that the study of this relationship is important in the present niche, considering that it reveals the importance of this right to be provided for in the legislation, declared as fundamental and the State responsible for the guarantee of this subjective public being.

Keywords: Training and human development. School education. Law. Historical-Cultural perspective.

\section{Los principios de la Actividad Orientadora de Enseñanza (AOE) y la Educación Escolar como derecho}

Resumen: En este artículo se comparte una investigación cuyos fundamentos teórico-metodológicos parten de la Perspectiva Histórico-Cultural en consonancia con el Materialismo Histórico-Dialéctico (MHD). Considera que el derecho a la educación escolar se deriva de ella y que tiene mayores implicaciones para 
la formación y el desarrollo humano. Así, busca presentar una investigación teórico-bibliográfica de la relación de los principios de la Actividad Orientadora de Enseñanza (AOE) y la educación escolar como derecho. La pregunta guía es: ¿cuál es la relación entre la AOE y la educación escolar como derecho? La investigación demuestra que los principios pautados por la AOE afirman la educación escolar como Actividad que busca la unidad entre el trabajo del profesor y del alumno preconizando la formación y el desarrollo humano para transformación de la sociedad. Considera que el estudio de esta relación es importante en el nicho actual, ya que desvela la importancia de este derecho estar previsto en la legislación, declarado como fundamental y el Estado responsable de la garantía de este ser público subjetivo.

Palabras clave: Formación y desarrollo humano. Educación escolar. Derecho. Perspectiva HistóricoCultural.

\section{Introdução}

O presente texto, derivado de uma pesquisa teórico-bibliográfica desenvolvida no âmbito do doutorado em Educação Matemática finalizado em 2020, fundamenta-se nos estudos da Perspectiva Histórico-Cultural originados das investigações de grupos de diferentes áreas do conhecimento, mas que tem em comum o Materialismo Histórico-Dialético (MHD) elaborado por Karl Marx (1818-1883) e Friedrich Engels (1820-1895) como método de investigação. Como decorrência, consideram o trabalho como uma Atividade orientada a um fim, isto é, um processo que constitui o ser humano como ser genérico distinguindo-se dos outros animais, sendo fonte de sua formação e desenvolvimento. Um desses grupos tinham como líder L. S. Vigotski (1896-1934) e como membros, dentre outros, A. R. Luria (1902-1977) e A. N. Leontiev (1903-1969).

O grupo de Vigostki investigou as Funções Psicológicas Superiores (FPS), tais como 0 pensamento lógico, a memória consciente e a vontade, que são resultantes de uma relação social compreendendo que o desenvolvimento humano sintetiza um longo e complexo processo histórico-social. Mesmo que existam as funções elementares definidas como as propriedades psíquicas legadas pela natureza e transmitidas filogeneticamente, todas as FPS são culturais, portanto, são edificadas pela vida social e não transmitidas geneticamente.

Assim, o trabalho é concebido como Atividade que tem uma estrutura dinâmica que se concretiza na cooperação entre todos. Partindo disso, o homem não nasce humano, torna-se humano, sendo a educação a condição primordial para isso, pois o "movimento da história só é, portanto, possível com a transmissão às novas gerações, das aquisições da cultura humana, isto é, com educação" (LEONTIEV, 1978, p. 273-283). A entrada na escola, para o autor, é concebida como Atividade, sendo que o estudo, assim como o brincar (infância) e 0 trabalho (adulto), denominam-se de Atividades-Guias que são "Atividade, cujo desenvolvimento governa as mudanças mais importantes nos processos psíquicos e nos traços psicológicos da personalidade da criança, em certo estágio de seu desenvolvimento" bem como, favorece o processo do 
desenvolvimento de outras Atividades tais como das outras Atividades-Guias (LEONTIEV, 1978, p. 293).

Diante disso, a educação escolar, hoje desenvolvida em uma instituição de ensino, acarreta implicações na formação e desenvolvimento humano e, segundo Cury (2002), deve ser declarada e defendida como um direito vislumbrando que seja "garantido como tal pelo poder interventor do Estado, no sentido de assegurá-lo e implementá-lo" (CURY, 2002, p. 259).

Partindo destas orientações teóricas-metodológicas, Moura (2000) concebe que a educação escolar surgiu pela necessidade de apropriação dos conceitos produzidos historicamente e considerados essenciais na sua constituição como unidade social e desencadeou a criação da Atividade Pedagógica que se constitui da unidade das Atividades-Guias do professor e do Aluno. Assim, propõe uma ação frente a organização do ensino, denominada de Atividade Orientadora de Ensino (AOE), cuja estrutura visa o desenvolvimento da Atividade Pedagógica.

Em exposto, a educação escolar é concebida como uma Atividade sendo indissociável da unidade indivíduo-sociedade vislumbrada como um direito. Desta maneira este artigo busca apresentar uma investigação teórico-bibliográfica da relação dos princípios da Atividade Orientadora de Ensino (AOE) e a educação escolar como direito, cujos fundamentos são os estudos da Perspectiva Histórico-Cultural em consonância com MHD, a fim de respondermos a pergunta "Qual a relação entre a AOE e a educação escolar como direito?".

O artigo foi organizado da seguinte maneira: apresentação breve sobre a trajetória da educação escolar como direito; os princípios da AOE; análise sobre as possíveis relações entre a educação escolar como direito e os princípios da AOE; e, por fim, algumas considerações finais.

\section{Breve trajetória da Educação escolar como direito}

Neste estudo, corrobora-se com Ranieri (2017), quando afirma que o direito à educação relaciona a unidade entre o indivíduo e a sociedade, e as contribuições desta se inter-relacionam a ambos desvelando que o "interesse particular e interesse público, assim, se fundem, da mesma forma que os interesses locais, regionais e nacionais" (RANIERI, 2017, p. 144).

No século XX, no documento da Organização das Nações Unidas (ONU), que trata da Declaração Universal dos Direitos do Homem, de 1948, há o reconhecimento do direito à educação. Esta organização tem origem em 1944 visando a reconstrução dos países europeus destruídos na segunda guerra mundial e, a partir dela, foram criados outros organismos ou agências internacionais multilaterais dos tipos monetário, comercial, financeiro e creditício. 
No entanto, a trajetória histórica da educação escolar "como forma de mobilidade social e de garantia de direitos" tem peculiaridades em cada país, sua declaração como direito previsto na legislação favorece na luta em responsabilizar o "Estado como provedor desse bem", isto é, que garanta a igualdade de oportunidades e intervenha "no domínio das desigualdades, que nascem do conflito da distribuição capitalista da riqueza, e progressivamente reduzir as desigualdades" (CURY, 2002, p. 259), em suas palavras:

\begin{abstract}
A declaração e a garantia de um direito tornam-se imprescindíveis no caso de países, como o Brasil, com forte tradição elitista e que tradicionalmente reservam apenas às camadas privilegiadas o acesso a este bem social. Por isso, declarar e assegurar é mais do que uma proclamação solene. Declarar é retirar do esquecimento e proclamar aos que não sabem, ou esqueceram, que eles continuam a ser portadores de um direito importante. Disso resulta a necessária cobrança deste direito quando ele não é respeitado (CURY, 2002, p. 259).
\end{abstract}

Em conclusão, o autor considera que a Constituição Brasileira de 1934 trouxe avanços para garantir o direito à educação, mas foi com a aprovação da Constituição Federal de 1988 (CF $B R, 1988)$ que a educação foi afirmada como um direito social, civil e político. Ranieri (2017) concorda com Cury destacando que, além das Constituição Federal de 1988 (CF BR, 1988), as normas internacionais, a e a Lei de Diretrizes e Bases de 1996 (Lei BR 9.394, 1996) favoreceram a compreensão de que o direito à educação "é um problema político; um problema que diz respeito à tomada de decisões coletivas, à legitimação e ao exercício do poder nas sociedades contemporâneas" (RANIERI, 2017, p.143).

De fato, a Constituição Federal de 1988 (CF BR, 1988) prevê a educação como um direito que deve ser garantido pelo Estado e a família e com a colaboração de toda a sociedade. No seu artigo 7, esclarece que "São direitos dos trabalhadores urbanos e rurais, além de outros que visem à melhoria de sua condição social", e no inciso IV estabelece o "salário-mínimo, fixado em lei, nacionalmente unificado, capaz de atender às suas necessidades vitais básicas e às de sua família com moradia, alimentação, educação, saúde, lazer, vestuário, higiene, transporte e previdência social, com reajustes periódicos que lhe preservem o poder aquisitivo, sendo vedada sua vinculação para qualquer fim".

Ao garantir que o Estado tem a responsabilidade de garantir o direito à educação básica obrigatória, a Constituição Federal de 1988 (CF BR, 1988) afirma, inicialmente, o direito público subjetivo, isto é, obrigatória e gratuita, que vislumbra a reivindicação deste caso seja negado, ao ensino fundamental, faixa etária dos 7 aos 14 anos. Com a aprovação da Lei de Diretrizes e Base da Educação Nacional (Lei BR 9394, 1996), que foi alterada por emenda constitucional em 2013, houve ampliação do direito público subjetivo para a faixa etária dos 4 aos 17 anos. 
Neste estudo, corrobora-se com Frigotto (2010) quando afirma que o Estado tem que ampliar o seu papel no direito público subjetivo da educação, que seu abandono traz consequência a toda sociedade, pois ela visa a formação e o desenvolvimento humano, como será apresentado a seguir onde busca-se analisar os princípios da AOE.

\section{Os fundamentos teóricos dos princípios da Atividade Orientadora de Ensino (AOE)}

Para estudar os princípios da AOE elaborada por Moura (1992) preconiza-se inicialmente compreender os fundamentos desta proposta cuja origem são os estudos da Perspectiva HistóricoCultural em consonância com MHD, com destaque aos estudos desenvolvidos por Leontiev (1978) que compreende que ao longo da existência o ser humano é marcado por três Atividades-Guias: o brincar na infância, o estudo, que inicia com a entrada na escola, e o trabalho na vida adulta.

Diante disso, caso a Atividade Guia seja desenvolvida ela "governa as mudanças mais importantes nos processos psíquicos e nos traços psicológicos da personalidade da criança, em certo estágio de seu desenvolvimento", bem como favorece o processo do desenvolvimento de outras Atividades tais como das outras Atividades-Guias (LEONTIEV, 1978, p. 293). Como todas as Atividades, se constituem de necessidades, motivos, ações, operações que se entrelaçam. Partindo disso, uma Atividade não pode ser compreendida se analisada separada da ação e, também, da maneira com que realizou a referida ação e sua condição, elemento esse denominado de operações.

O próprio Leontiev (1978) escreve que somente o ser humano desenvolve uma Atividade, que são "os processos que são psicologicamente caracterizados pelo fato de aquilo para que tendem no seu conjunto (o seu objeto) coincidir sempre com o elemento objetivo que incita 0 paciente a uma dada Atividade, isto é, com o motivo" (LEONTIEV, 1978, p. 296). O autor sustenta que toda Atividade inicia por uma necessidade, sendo resultante de um processo histórico, mas ela não orienta a estrutura das atividades, pois é no objeto que a necessidade encontra a determinação que lhe possibilita se objetivar, isto é, existir

Assim, as necessidades e motivos não podem ser considerados sinônimos, mesmo que os motivos sejam os responsáveis por indicar os meios objetivos para que as necessidades possam ser atendidas, nem sempre elas coincidem com o motivo, que podem ser: sem geradores de sentido ou estímulos. Os motivos geradores de sentido são aqueles que coincidem com objeto da Atividade preconizando que esta desenvolva, ao contrário dos motivos estímulos. 
Diante disso, quando há um conjunto de ações articuladas por uma necessidade, nas quais coincidem motivo e objeto, tem-se um motivo gerador de sentido que levam à uma Atividade. Portanto, instituindo a consciência, sendo que ela se constitui a partir de processos históricos sociais e da vida material, possibilitando a separação entre o fenômeno e a essência da coisa e, consequentemente, obtendo o conhecimento teórico do objeto.

Na Perspectiva Histórico-cultural, em consonância com o MHD o conhecimento teórico da realidade é a condição para o ser humano conseguir agir e transformá-la, mas este não se apresenta como um objeto que basta, apenas, analisar, intuir para obtê-lo, mas é a partir do "movimento dos fenômenos da realidade objetiva que determina o movimento do pensamento" (KOSIK, 1976, p. 35). E para que "o pensamento possa progredir do abstrato ao concreto, tem de mover-se no seu próprio elemento, isto é, no plano abstrato, que é negação da imediatidade da evidência e da concreticidade sensível" (KOSIK,1976, p. 26).

O concreto será compreensível por meio da mediação do abstrato, e o todo, por meio da mediação da parte, pois a "mediação dialética é uma metamorfose na qual se cria o novo, é a gênese do qualitativamente novo". Assim, "a ascensão do abstrato ao concreto é um movimento para qual todo início é abstrato cuja dialética consiste na superação desta abstratividade" (KOSIK,1976, p. 26-30). A consciência se constitui da unidade dialética do "conhecimento explícito, justificado, racional e teórico" e no aspecto totalmente intuitivo que se interpenetram e influenciam, reciprocamente, portanto, a história criada pelo homem é verdadeira, bem como que ela "se liga ao trabalho e aos resultados obtidos pelas gerações precedentes" (KOSIK, 1976, p. 218).

A consciência se constitui tendo como base o "reflexo da realidade independentemente da relação individual ou pessoal do homem a esta", isto é, os significados, que é "refletida e fixada na linguagem, o que lhe confere a sua estabilidade". E confere, também, sentido pessoal que é 0 responsável em traduzir "precisamente a relação do sujeito com os fenômenos objetivos conscientizados" e os conteúdos sensíveis que são representações, imagens de percepção, sensações (LEONTIEV, 1978, p. 94).

Neste sentido, o desenvolvimento de uma Atividade vislumbra a instituição de consciência fonte da formação e desenvolvimento humano sendo que o conhecimento teórico se expressa em modos de Atividade e sua apropriação visa movimentar o pensamento, indo do abstrato ao concreto mobilizando o processo de elaboração do pensamento teórico que entrelaça abstração, generalização e formação de conceitos e também assevera que há diferença entre o pensamento 
empírico o "qual apanha o objeto de conhecimento apenas nas suas propriedades exteriores, desconectado de suas relações com outros objetos" (LIBÂNEO, 2016, p. 360).

Cumpre lembrar que a apropriação é uma Atividade cujo processo "realiza a necessidade principal e o princípio fundamental do desenvolvimento ontogênico humano - a reprodução nas aptidões e propriedades do indivíduo" (LEONTIEV, 1978, p. 172). Assim, apropriação interrelaciona com a objetivação que é produto da Atividade "só apropriando-se delas, no decurso de sua vida, ele adquire propriedades e faculdades verdadeiramente humanas. Este processo colocao, por assim dizer, aos ombros das gerações anteriores e eleva-o muito acima do mundo animal" (LEONTIEV, 1978, p. 282).

O autor compreende que o pensamento em sentido próprio, é "o processo de reflexo consciente da realidade, nas suas propriedades, ligações e relações objetivas, incluindo mesmo os objetos inacessíveis à percepção sensível imediata" (LEONTIEV, 1978a, p. 84). Portanto, concebe o pensamento com conceitos como imprescindível para o ser humano compreender 0 mundo objetivo, indo além da sua aparência fenomênica, indo à essência.

Desse modo, a formação e o desenvolvimento humano não ocorrerá "caso ele seja privado de condições sociais de vida e de educação, isto é, de um acervo de objetivações a se apropriar" (MARTINS, 2016, p. 49) e o desenvolver uma Atividade preconiza a instituição de consciência, o significado desta que é histórico e deve coincidir com o sentido pessoal.

Partindo disso, o significado do estudo, que é Atividade-Guia do aluno, vislumbra apropriação dos conteúdos escolares que são objetivações produzidas pela humanidade para a transformação da sociedade., Segundo Moura (2017), a unidade entre Atividade do aluno e 0 trabalho do professor constitui a Atividade Pedagógica, esquematizada na Figura 1. 
Figura 1: Estrutura da Atividade pedagógica

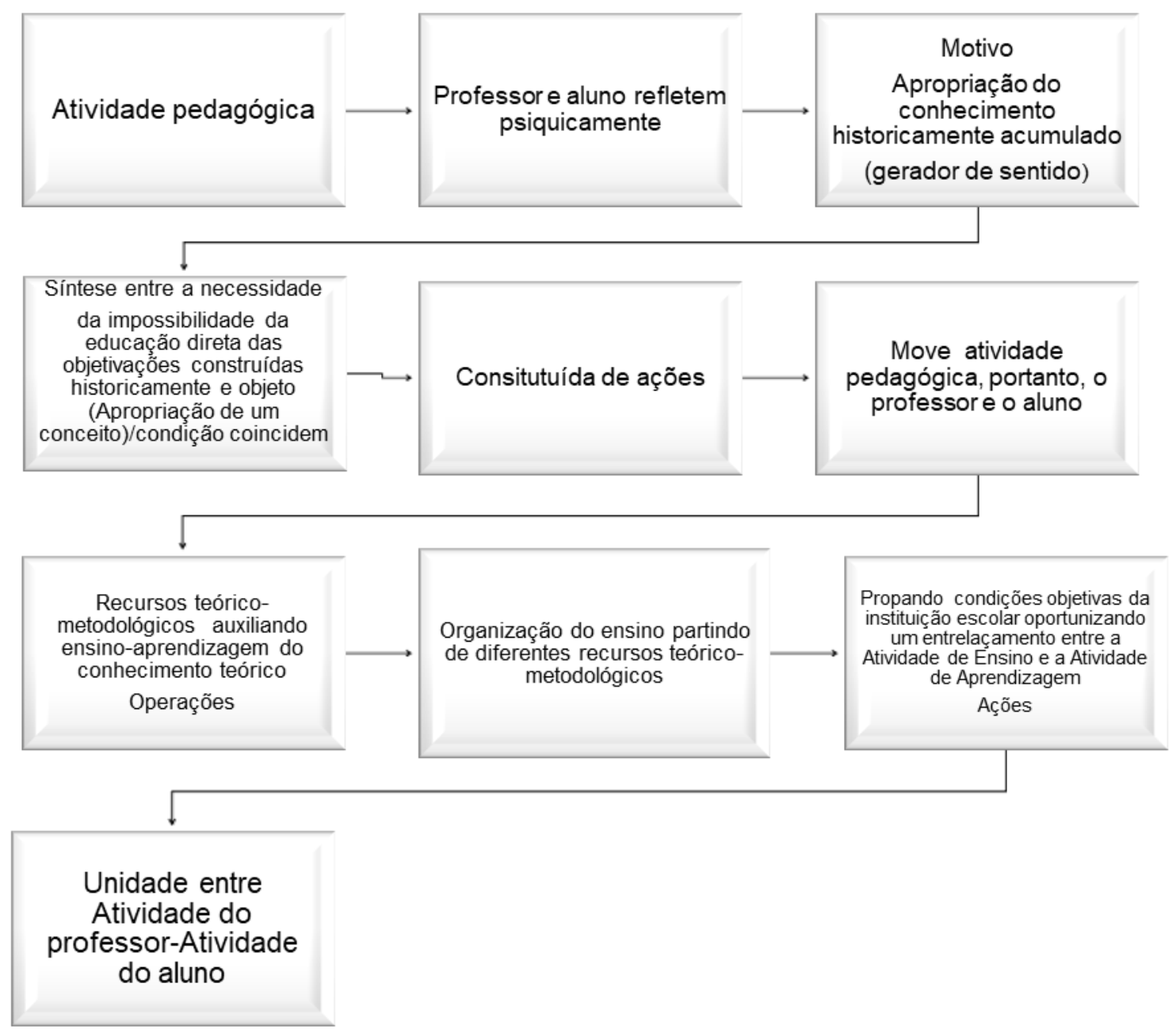

Fonte: Elaborado pelas autoras.

Como esquematizado, a Atividade Pedagógica visa a educação escolar como Atividade, sendo formada por duas dimensões que se entrelaçam compondo-se em uma unidade: Atividade do professor e a atividade do aluno, portanto, a inter-relação entre as Atividades-Guias do aluno e do professor. Moura (2017) denomina a Atividade do professor de Atividade de Ensino e a do aluno de Atividade de aprendizagem sendo a "educação como o modo humano de generalizar as aprendizagens adquiridas nas vivências individuais e coletivas na solução de problemas autênticos que surgem em atividades" (MOURA, 2017, p. 112)

Neste sentido, a Atividade de ensino vislumbra mobilizar "os sujeitos que vierem a tomar parte dessa estrutura social ou por ter nascido nela ou por ter a ela se incorporado por alguma outra razão" contribuindo para que estes "possam se apropriar dos conhecimentos já produzidos e que são essenciais para a sua constituição como unidade social". O significado desta Atividade indica como essencial que "ensina algo que existe como produto das relações entre os homens em atividades concretas advindas da vida em sociedade" (MOURA, 2017, p.103). Com relação a 
Atividade de aprendizagem é importante destacar que ela visa apropriação das objetivações produzidas pela humanidade e ocorrem em diferentes ambientes sociais, sendo a escola um destes ambientes e tem peculiaridades especiais ocorre em diferentes ambientes sociais.

Em exposto, a unidade entre o trabalho do professor e a Atividade do aluno constitui a Atividade pedagógica vislumbrando a educação escolar como Atividade que afirma o movimento dialético entre estas atividades, desencadeando a unidade entre elas. Neste movimento vislumbrase a Atividade Orientadora de Ensino, sendo que, nas palavras de Moura; Sforni; Lopes (2017):

[...] 0 professor, ao se colocar no movimento de organização da AOE para propiciar a aprendizagem de um conteúdo, parte de uma visão de que existe um modo de organizar o ensino - um modo geral de ação - que permite que ocorra uma aprendizagem de melhor qualidade. A organização da atividade direcionada a um fim assume a qualidade de atividade orientadora pelo seu caráter mediador da atividade de aprendizagem, nas relações criadas entre o sujeito, o objeto e as ações desenvolvidas para solucionar o problema na situação desencadeadora de aprendizagem. A relação entre objeto idealizado e objeto concretizado é que dá 0 movimento na $A O E$ que está em processo de solução do problema (MOURA; SFORNI; LOPES, 2017, p. 96-97)

O aspecto essencial da AOE é uma Situação desencadeadora da Aprendizagem (SDA), que implica na proposição de um problema que "deve contemplar a necessidade da humanidade que levou à sua construção, sendo que a solução conterá, também, a forma com que os homens foram se organizando para satisfazer essa necessidade" (MOURA; SFORNI; LOPES, 2017, p. 91). A materialização da SDA vislumbra recursos, entre eles, que envolvam a história virtual do conceito e situações emergentes do cotidiano.

A história virtual do conceito "é compreendida como uma narrativa que proporciona ao estudante envolver-se na solução de um problema como se fosse parte de um coletivo que busca solucioná-lo, tendo como fim a satisfação de uma determinada necessidade, à semelhança do que pode ter acontecido em certo momento histórico da humanidade" (MOURA et al., 2010, p. 105). As situações emergentes do cotidiano partem de uma problematização que desencadeia ao ser humano diante da necessidade de vivenciar solução de problemas.

No próximo item analisa-se a relação dos princípios da AOE com a educação escolar como direito social.

\section{Os princípios da AOE para educação escolar como direito}

Os fundamentos teóricos que originaram a $\mathrm{AOE}$ têm como princípio o conceito de Atividade, portanto, concebe que o humano é o resultado do entrelaçamento do aspecto individual, 
no sentido biológico, com o social, no sentido cultural. Assim, será a partir do "processo de apropriações e objetivações, viabilizado por meio do trabalho, que o indivíduo torna-se humano ao longo de sua vida em sociedade, ao apropriar-se da essência humana, que é um produto históricocultural (MOURA org., 2010, p. 19).

Os princípios da AOE, compreendem a importância da educação escolar no processo de formação e desenvolvimento humano, e pode ser concebido como um modo de ação generalizado para se organizar o ensino, que medeia a relação entre o professor e o aluno "de forma que sua dimensão orientadora conduza intencionalmente ao desenvolvimento", assim, há uma interrelação entre "Atividade, Orientação e Ensino" (ARAÚJO, 2019), como esquematizado na Figura 02.

Figura 02: Proposta da Atividade Orientadora de Ensino (AOE)

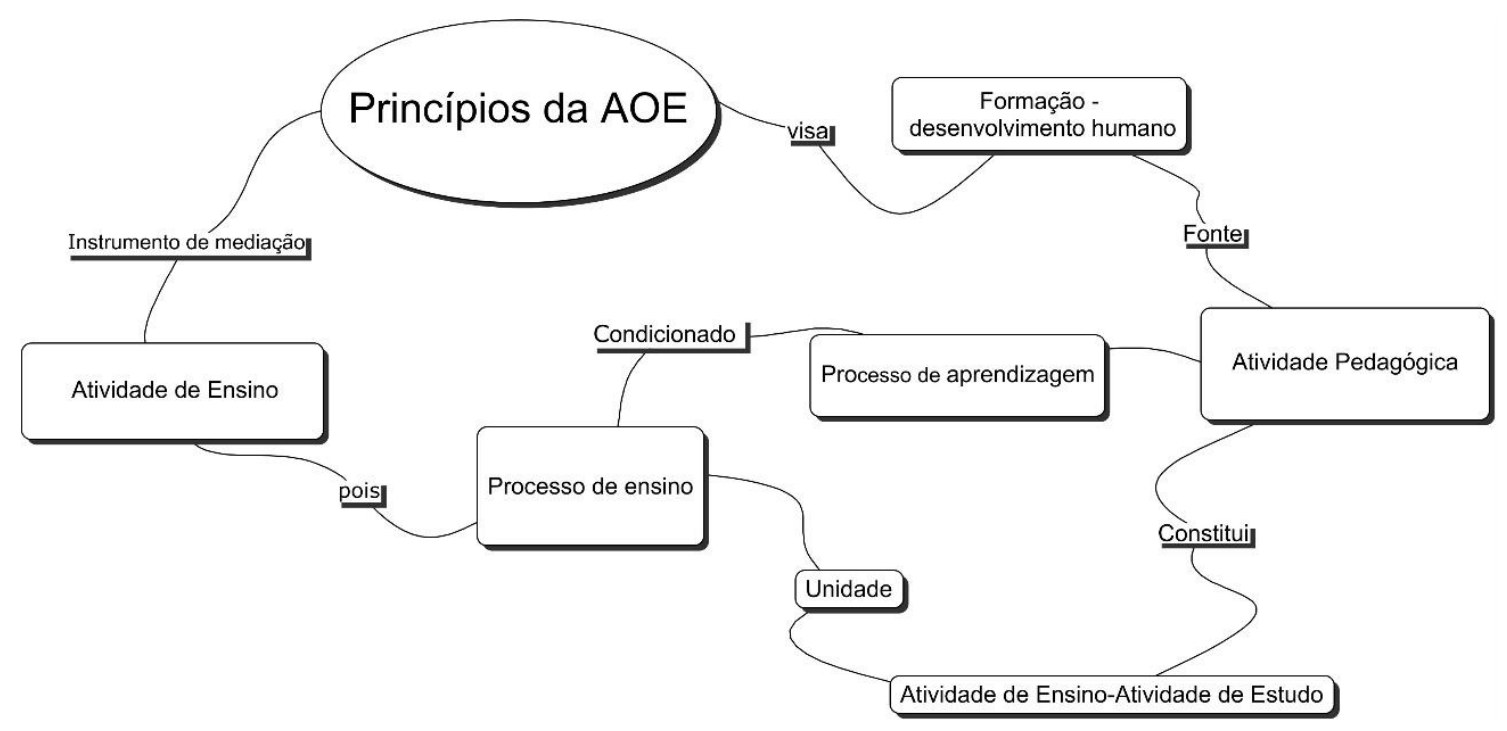

Fonte: Elaborado pelas autoras

Como esquematizado, os princípios da $\mathrm{AOE}$, visam o desenvolvimento da Atividade Pedagógica, portanto, da educação escolar como uma Atividade cuja constituição tem origem da unidade entre as Atividades-guias do professor e do aluno, corroborando para que o ser humano se forme e se desenvolva historicamente. Assim, a AOE mobiliza um movimento dialético que articula a Atividade do professor com a do aluno considerando que terão problemas distintos a resolver. O primeiro é o do professor, que terá que organizar o ensino, portanto, definir ações (de ensino), a partir da manifestação de uma necessidade que se objetiva por meio da aprendizagem do estudante. Logo, o problema do aluno se refere a aprender o que o professor ensina.

A unidade dialética no processo de ensino e aprendizagem preconiza uma Atividade, portanto, parte do conceito de trabalho como uma Atividade orientada a um fim, fonte de formação 
e desenvolvimento humano. 0 ensino e o desenvolvimento constituem-se como unidade de contrários, ou como polos opostos interiores um ao outro, de modo que um afirmará a existência pela presença de seu contrário. Ou seja, só há desenvolvimento se houver ensino, assim, como só há ensino se houver aprendizagem, e no "processo de ensino estão contidas as possibilidades de desenvolvimento concreto em cada momento histórico da vida de cada pessoa" (MAGALHÃES; MARTINS, 2020, p. 4).

Os princípios da $\mathrm{AOE}$ corroboram que a apropriação dos conhecimentos historicamente sistematizado materializa-se na unidade entre ensino e aprendizagem. Portanto, a educação escolar como Atividade "permitirá a apropriação de um modo de se fazer humano ao se apropriar de conceitos produzidos histórica e culturalmente" (MOURA, 2017, p. 116). Assim sendo, 0 trabalho desenvolvido pelo professor - a sua Atividade - está dirigido a um fim, ao ato de ensinar e sua necessidade consiste em organizar o ensino para concretizá-lo. Portanto, ele é um trabalhador que projeta seu objetivo e seu fim, sendo suas ações orientadas para satisfazer uma necessidade, a de ensinar visando a transformação da sociedade.

Partindo dos já referidos princípios, a estrutura da AOE mobiliza os professores ao organizar o ensino, compreendendo que o conceito é o resultado de um processo longo de conhecimento e o pensamento com conceitos favorece o desenvolvimento das FPS. Esse desenvolvimento movimenta o pensamento, indo do abstrato ao concreto favorecendo 0 pensamento teórico, ao contrário do pensamento empírico que aparecerá e se desenvolverá ao longo da vida cotidiana dos seres humanos interdependente da educação escolar.

Ao analisar os princípios da $\mathrm{AOE}$ é possível identificar que corroboram com o direito à educação visa apropriação da cultura negando o determinismo da natureza humano, este direito reconhece que os conhecimentos sistematizados favorecem ao ser humano "se apossar de padrões cognitivos e formativos pelos quais tem maiores possibilidades de participar dos destinos de sua sociedade e colaborar na sua transformação" (CURY, 2002, p. 260).

O estudo da relação entre o princípios da $A O E$ e a educação como direito, Levam à compreensão que o ser humano se forma e desenvolve historicamente, que as "desigualdades entre os homens não provém das suas diferenças biológicas naturais", mas sua origem é do "produto da desigualdade econômica, da desigualdade de classes e da diversidade consecutiva das suas relações com as aquisições que encarnam todas as aptidões e faculdades da natureza humana, formadas no decurso de um processo sócio-histórico" (LEONTIEV, 1978, p. 274). Assim, contribui para a compreensão que a educação escolar visa a formação e desenvolvimento humano, consequentemente, que esta deve ser um direito público subjetivo. 


\section{Considerações Finais}

O artigo teve o propósito de apresentar uma investigação teórico-bibliográfica da relação dos princípios da Atividade Orientadora de Ensino (AOE) e a educação escolar como direito, fundamenta-se na Perspectiva Histórico-Cultural em consonância com MHD. A pesquisa demonstrou que a Constituição Federal de 1988 (CF BR, 1988), reconhece o direito à educação deixando subtendido que ela é apropriação da cultura, negando o determinismo da natureza humana. Assim como os estudos da Perspectiva Histórico-Cultural que fundamentaram a elaboração da $\mathrm{AOE}$ que compreende que a formação e o desenvolvimento humano é resultante da unidade individual e social.

O trabalho do professor é essencial para a concretização do desenvolvimento humano. Ao ser organizado, partindo de SDA, que é ação nuclear da AOE, vislumbra a educação escolar como Atividade e sua constituição ocorre da unidade entre as Atividades-Guias do professor e do aluno. $O$ ensino se desenvolve na $A O E$, e a educação escolar e o trabalho do professor surgiram como uma necessidade humana. Assim, na Atividade de ensino - que é o trabalho docente - ao satisfazer a sua necessidade de organizar o ensino, de maneira mais ampla, o professor satisfaz também a necessidade da sociedade de criar condições para que os sujeitos (estudantes) se apropriem dos conhecimentos culturais produzidos historicamente, condição esta para sua humanização e o desenvolvimento da sociedade.

A Atividade do professor e do aluno se efetivarão quando houver uma unidade entre elas, e a estrutura da AOE mobiliza a apropriação das objetivações consideradas essenciais para 0 desenvolvimento das capacidades intelectivas. Portanto, pode se configurar como uma base teórico-metodológica para o desenvolvimento das Atividades-Guias do professor e do aluno, vislumbrando o desenvolvimento da educação escolar como uma Atividade, consequentemente, a aprendizagem visa o desenvolvimento.

Os princípios da $\mathrm{AOE}$ preconizam uma base teórico-metodológica que mobiliza 0 professor a compreender que seu trabalho inter-relaciona-se com a Atividade do Aluno e, ainda, leva à compreensão da educação escolar como Atividade indissociável da unidade individuosociedade, sendo essencial na constituição do ser humano como sujeitos que faz e vive a história. Em síntese, e para concluir, o estudo contribuiu na compreensão de que a educação escolar deve ser declarada como um direito universal no qual todos os seres humanos têm o direito à apropriação cultural, de maneira igualitária. Para tanto, deve ser pública e gratuita e o Estado 0 responsável em garantir que este seja um direito público subjetivo. 


\section{Referências}

ARAÚJO, Sampaio Elaine. Atividade orientadora de ensino: princípios e práticas para organização do ensino de matemática. RPEM, Campo Mourão, v.8, n.15. jun. 2019. DOI: https://doi.org/10.33871/22385800.2019.8.15.123-146

BRASIL. Lei $\mathrm{n}^{\circ}$. 9.394, de 20 de dezembro de 1996. Estabelece as diretrizes e bases da educação nacional. Diário Oficial da União, Brasília, 23 dez. 1996.

BRASIL. Constituição: República Federativa do Brasil. Brasília: Centro Gráfico, 1988.

CURY, Carlos Roberto Jamil. Direito à educação: direito à igualdade, direito à diferença. Cadernos de Pesquisa, n. 116, p. 245-262, julho/ 2002. DOI: https://doi.org/10.1590/S010015742002000200010

FRIGOTTO, Gaudêncio. A produtividade da escola improdutiva: um (re)exame das relações entre a educação e a estrutura econômico-social capitalista. 9. ed. São Paulo: Cortez, 2010.

KOSIK. Karel. A Dialética do Concreto. 2. ed. Tradução de Célia Neves e Alderico Toríbio. Rio de Janeiro: Paz e Terra, 1976.

LEONTIEV, Alexis Nikolaevich. Desenvolvimento do psiquismo. Lisboa: Livros Horizonte, 1978.

LIBÂNEO, José Carlos. Formação de Professores e Didática para Desenvolvimento Humano. Educação \& Realidade [online], Porto Alegre, v. 40, n. 2, p. 629-650. Epub Mar 20, 2016. DOI: https://doi.org/10.1590/2175-623646132.

MAGALHÃES, Giselle Modé; MARTINS, Ligia. M. Onze teses sobre a relação entre psicologia educacional e pedagogia escolar. Revista Educação em Questão, Natal, v. 58, n. 55, 7 fev. 2020. DOI: https://doi.org/10.21680/1981-1802.2020v58n55ID19150

MARTINS, LIGIA. Elementos Fundamentais da Prática Pedagógica. In: MESQUITA, Afonso Mancuso; FANTIN, Fernanda Carneiro Bechara; ASBAHR, Flávia Ferreira da Silva (Orgs.) Currículo Comum para o Ensino Fundamental Municipal. Bauru: Prefeitura Municipal de Bauru, 2016.

MOURA, Manoel Oriosvaldo; SFORNI, Marta Sueli de Faria; LOPES, Anemari Roesler Luersen Vieira. A objetivação do ensino e o desenvolvimento do modo geral da aprendizagem da atividade pedagógica. In: MOURA, Manoel Oriosvaldo. (Org.). Educação escolar e pesquisa na teoria histórico-cultural. São Paulo: Edições Loyola, 2017.

MOURA, Manoel Oriosvaldo. A objetivação do currículo na atividade pedagógica. Obutchénie: R. de Didat. e Psic. Pedag. Uberlândia, v.1, n.1, p.98-128, jan./abr. 2017. DOl: http://dx.doi.org/10.010101/XXXXX2017-5.

MOURA, Manoel Oriosvaldo (orgs.). A atividade pedagógica na teoria Histórico-Cultural. Brasília: Liber livro, 2010.

MOURA, Manoel Oriosvaldo. 0 educador matemático na coletividade de formação: uma experiência com a escola pública. 2000. 131f. Tese (Livre Docência em Educação) - Faculdade de Educação, Universidade de São Paulo, São Paulo, 2000. 
MOURA, Manoel Oriosvaldo. A construção do signo numérico em situação de ensino. 1992, 151f. Tese (Doutorado em Educação: Ensino de Ciências e Matemática) - Universidade de São Paulo, 1992.

RANIERI, Nina Beatriz Stocco. 0 novo cenário jurisprudencial do direito à educação no Brasil: 0 ensino domiciliar e outros casos no Supremo Tribunal Federal. Pro-Posições, Campinas, v. 28, n. 2 (83), Maio/Ago. 2017Doi: https://doi.org/10.1590/1980-6248-2016-0008 